\title{
Prerequisites for Increasing the Axle Load on Railway Tracks in the Czech Republic
}

\author{
M. Lidmila, L. Horníček, H. Krejčiříková, P. Tyc
}

This paper deals with problems of increasing the axle load on Czech Railways (ČD) tracks to $250 \mathrm{kN}$ or $300 \mathrm{kN}$, respectively. The results of a numerical analysis of the effects of increased axle loads on the track bed structure were verified by experimental measurements carried out on track bed construction models in an experimental box on a 1:1 scale. The results of the research are applicable for routine use on $\breve{C} D$.

Keywords: axle load, permanent way, track bed, model measurement, substructure.

\section{Introduction}

In 2005 and 2006, as part of a grant-founded project of the Ministry of Transport of the Czech Republic, the Department of Railway Structures of the Faculty of Civil Engineering CTU in Prague was engaged in research on project No. 1F52H/052/130 "Methodology of Transitional Parameters for the Construction of the Substructure on Tracks of the Conventional Trans-European System”. The objective of this research project was to elaborate the structural layout principles for the permanent way and the substructure to enable an increase in axle loads to $250 \mathrm{kN}$ and $300 \mathrm{kN}$.

The passage of railway carriages on the rail tracks in the Czech Republic depends basically on the load-bearing capacity of the bridge structures. However, problems of the load-bearing capacity of bridge structures exposed to an increased load acting on the axle did not form part of the specifications for the research to carried out in the framework of this Ministry of Transport project.
In order to fulfil the research objective, a detailed numerical analysis of the effect of an increased axle load on the permanent way and track bed structure was selected, complemented with experimental measurements on four track bed models. The effect of an increased axle load was determined by measuring the sleeper deflection and the track bed structure.

\section{Materials and methods}

\subsection{Numerical analysis of the effects of an increased axle load on track bed structures}

The first step was to assess the rail load-bearing capacity using the methodology specified in the Instruction CD S3 "Permanent way". This proved that with an increase of:

1. Axle load to $250 \mathrm{kN}$ and $300 \mathrm{kN}$, the requirements are met by rail shapes of S46, UIC 60 and R65 type in spliced

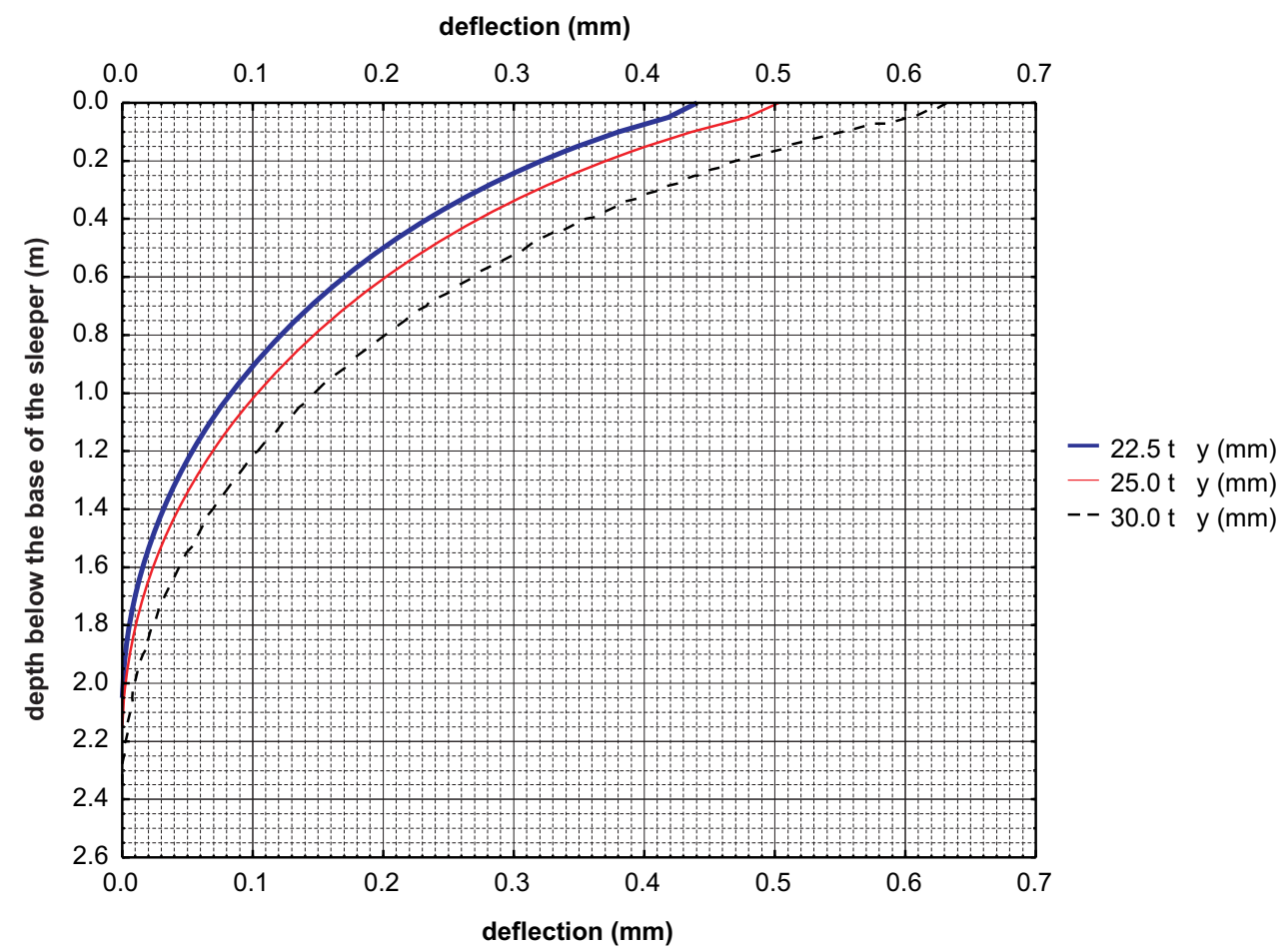

Fig. 1: Track bed deflection pattern due to permanent way loading with an axle load of $22.5 \mathrm{t}-25.0 \mathrm{t}-30.0 \mathrm{t}\left(\mathrm{gravel} E_{\mathrm{def}}=100 \mathrm{MPa}\right)$ 
rail even in the case of poor track bed quality (loading capacity coefficient $C=20-50 \mathrm{MPa} \cdot \mathrm{m}^{-1}$ ).

2. Axle load to $250 \mathrm{kN}$, the requirements are met by UIC rails in long-welded rail even in the case of poor track bed quality (loading capacity coefficient $C=20-50 \mathrm{MPa} \cdot \mathrm{m}^{-1}$ ). For loading by $300 \mathrm{kN}$, the requirements are met only by track beds with loading capacity coefficients of $100 \mathrm{MPa} \cdot \mathrm{m}^{-1}$ and more.

3. Axle load to $250 \mathrm{kN}, \mathrm{S} 49$ rails may be used only for vertical rail head wear of up to $20 \mathrm{~mm}$ in track beds with loading capacity coefficients of $100 \mathrm{MPa}^{-1}$ and more. For loading by $300 \mathrm{kN}$, the use of $\mathrm{S} 49$ rail shape in long-welded rail is not advisable.

The use of concrete sleepers in the permanent bed construction depends on the design of the sleeper structure. The sleepers in use on ČD B $91 \mathrm{~S}$ corridor tracks are dimensioned for loading by an axle force of $250 \mathrm{kN}$. For loading by $300 \mathrm{kN}$, an assessment of the sleeper reinforcement would be necessary.

The effect of an increased axle load on the track bed structure was determined by means of numerical analysis for calculating the deflections and stresses using the finite-element method. In calculations of deflections of longitudinal structures, simpler two-dimensional models are commonly used. This solution can be made on the assumption that the load is constant in the longitudinal axis of the structure, or is at least sufficiently long. However, this assumption is not fulfilled, because the changing load for 7 consecutive sleepers with a distance of $600 \mathrm{~mm}$ between the axes is required. For this reason, three-dimensional models of a railway track segment were created in Plaxis Tunnel 3D software. Within the next period of the solution it turned out to be necessary to carry out a parametric study, because calculations of three-dimensional models were excessively time-consuming.

The computations were made with software developed by a.s. Stavební geologie - Geotechnika Praha. Fig. 1 shows the track bed deflection pattern for permanent bed loading with axle loads of $22.5 \mathrm{t}-25.0 \mathrm{t}-30.0 \mathrm{t}$. Fig. 2 displays the stress pattern in the track bed for loading of the permanent way with axle loads of $22.5 \mathrm{t}-25.0 \mathrm{t}-30.0 \mathrm{t}$.

Fig. 1 implies that when the weight acting on the axle is increased from 22.5 t to $25.0 \mathrm{t}$, the substructure subgrade, i.e. at a depth of $35 \mathrm{~cm}$ below the sleeper loading area, is exposed to a $16 \%$ increase in deflection, and when the weight is increased from 22.5 t to 30.0 t the substructure subgrade shows a $52 \%$ increase in deflection.

\subsection{Model measurements in an experimental box}

The effect of an increased axle load on increased deflection of the track bed was determined on four models of track bed structures on a 1:1 scale placed in an experimental box with inside dimensions of $2100 \times 990 \times 800 \mathrm{~mm}$ (Fig. 3).

Table 1: Specification of track bed construction models and their characteristics

\begin{tabular}{|c|c|c|}
\hline Model specification & Granulated gravel layer thickness in $\mathbf{~ m m}$ & Ballast bed thickness in $\mathbf{~ m m}$ \\
\hline 15SD E10 & 150 & 350 \\
\hline 30SD E10 & 300 & 350 \\
\hline 15SD E25 & 150 & 350 \\
\hline 30SD E25 & 300 & 350 \\
\hline
\end{tabular}

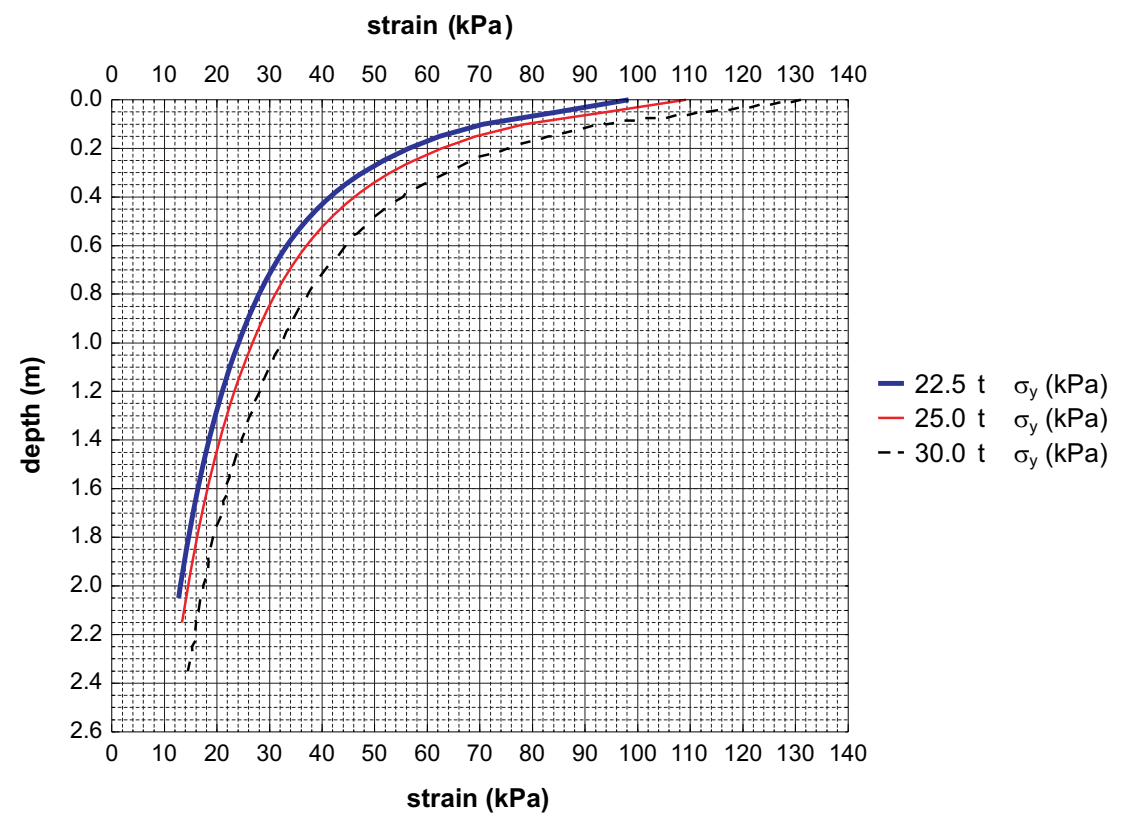

Fig. 2: Stress pattern in the track bed due to permanent way loading with an axle load of $22.5 \mathrm{t}-25.0 \mathrm{t}-30.0 \mathrm{t}\left(\right.$ gravel $\left.E_{\text {def }}=100 \mathrm{MPa}\right)$ 

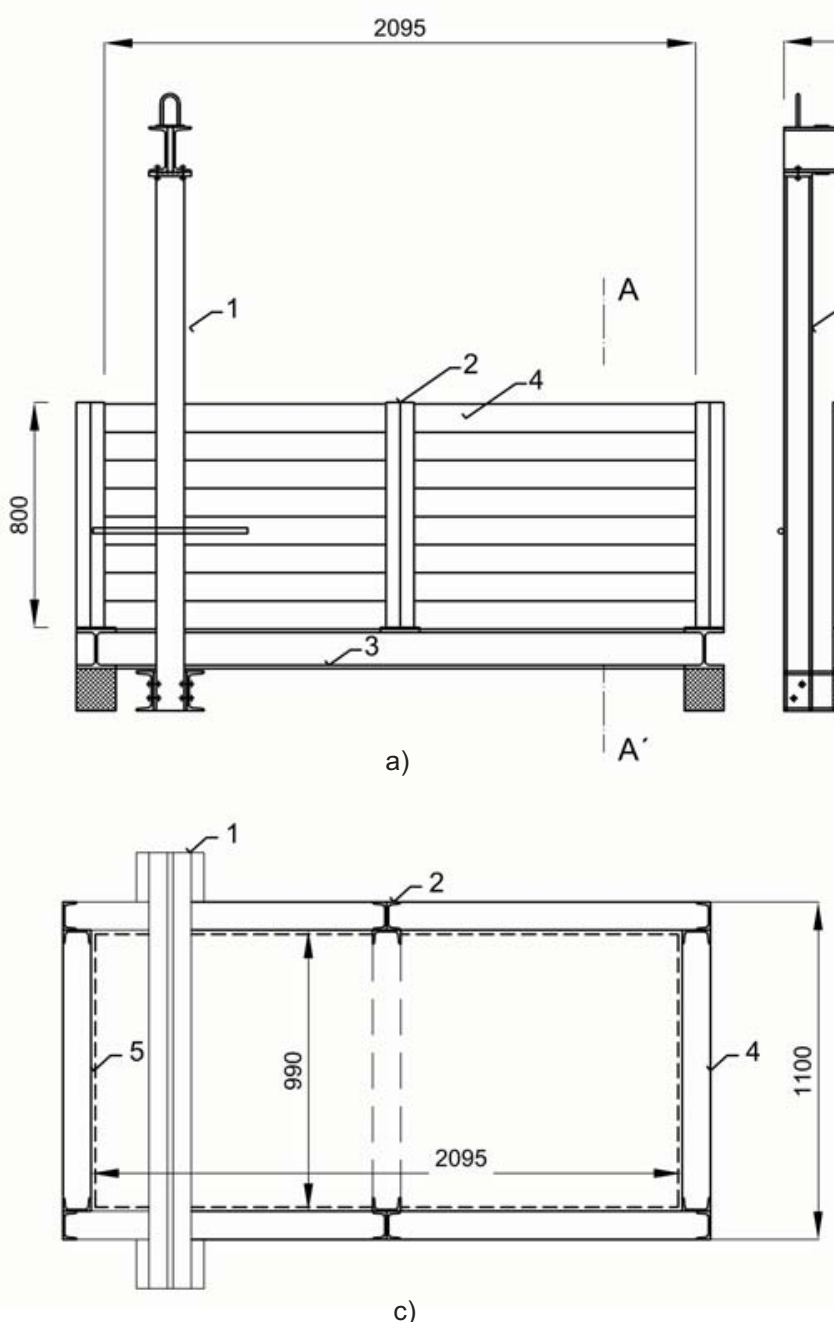

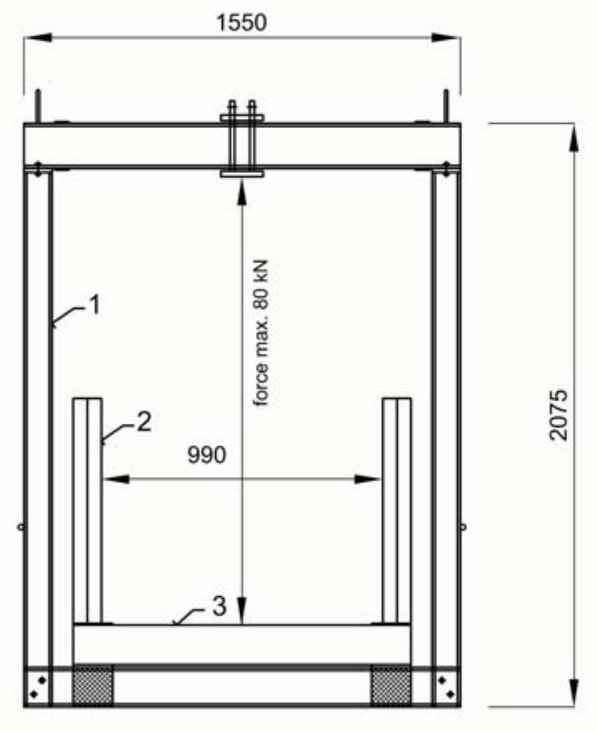

b)

\section{Legend:}

1) load frame

2) steel construction of box walls

3) steel construction of box bottom

4) wooden side-panels covering

5) sheet metal th. $0,55 \mathrm{~mm}$

Fig. 3: Basic dimensions of the experimental box: a) side view, b) cross section, c) ground plan

The main characteristics of the track bed model structures are specified in Table 1. The model specifications include the granulated gravel thickness in $\mathrm{cm}$ and the value of the modulus of deformation of the subgrade, simulated by rubber plates (e.g. model 15SD E10 implies a model with a layer of granulated gravel $15 \mathrm{~cm}$ in thickness and the load bearing capacity of rubber plates $\left.E_{r}=10.9 \mathrm{MPa}\right)$. Individual models were selected so as to characterize different load-bearing capacities (moduli of deformation values) on the substructure subgrade $E_{p l}$ (see Table 2).

Track bed model structures of Type 2 were composed of one half of a sleeper mounted on a ballast bed $350 \mathrm{~mm}$ in thickness. The ballast bed was laid on a layer of granulated gravel $150 \mathrm{~mm}$ or $300 \mathrm{~mm}$ in thickness. The structural layer of granulated gravel was placed on rubber plates laid at the bottom of the experimental box. The rubber plates simulated the subgrade with a load-bearing capacity of $10.9 \mathrm{MPa}$ and 25.0 MPa (see Table 2).

The structural layer of granulated gravel graded $0 / 32 \mathrm{~mm}$ was compacted with a special manual vibratory compacting unit with a compacting area of $174 \times 174 \mathrm{~mm}$. The granulated gravel layer was compacted in layers $150 \mathrm{~mm}$ in thickness. The time for compacting one layer was set to 30 minutes to achieve perfect compaction along the whole surface of the

Table 2: Values of moduli of deformation on structural layers of model constructions

\begin{tabular}{|c|c|c|c|}
\hline \multirow{2}{*}{ Model specification } & \multicolumn{3}{|c|}{ Moduli of deformation in MPa } \\
\cline { 2 - 4 } & $\boldsymbol{E}_{\boldsymbol{r}}$ & $\boldsymbol{E}_{\boldsymbol{p l}}$ & $\boldsymbol{E}_{\boldsymbol{p} \boldsymbol{p}}$ \\
\hline 15SD E10 & 10.9 & 26.1 & 63.8 \\
\hline 30SD E10 & 10.9 & 53.3 & 79.4 \\
\hline 15SD E25 & 25.0 & 50.1 & 90.0 \\
\hline 30SD E25 & 25.0 & 82.9 & 103.9 \\
\hline
\end{tabular}




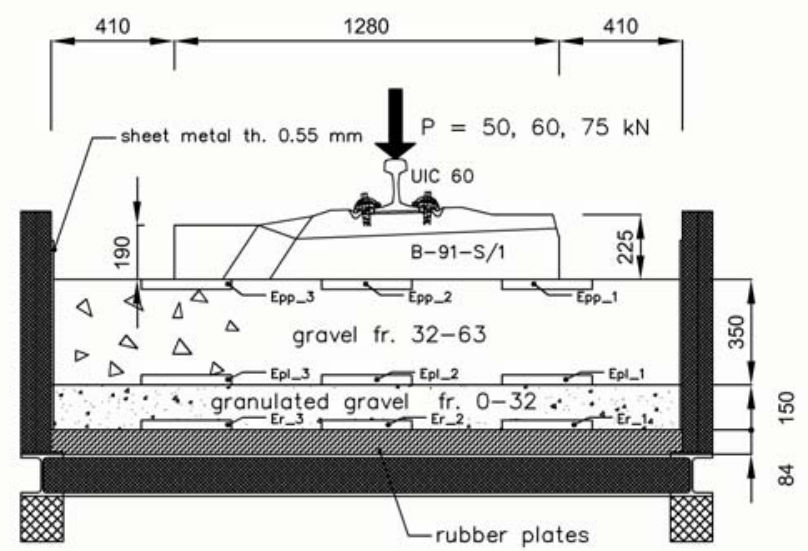

a)

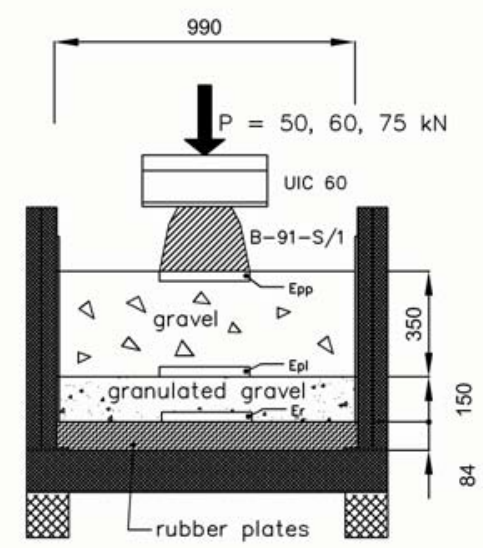

b)

Fig. 4: Model 15 SD E10 in the experimental box: a) longitudinal section, b) cross section

layer. Compaction of the granulated gravel was checked by measuring the modulus of deformation. The values of the moduli of deformation are given in Table 2.

On top of the structural layer of granulated gravel, a ballast bed of gravel graded $32 / 63 \mathrm{~mm}$ with a thickness of $350 \mathrm{~mm}$ was laid. The ballast bed structure was divided into two layers, each cca $175 \mathrm{~mm}$ in thickness. Each layer of gravel was again compacted for 30 minutes running uniformly along the whole surface of the experimental box. The total ballast bed thickness under the sleeper loading area after compaction reached the value of $350 \mathrm{~mm}$ specified for concrete sleepers. The measured values of the moduli of deformation $E_{p p}$ are given in Table 2.

The ballast bed surface served for mounting one half of an instrumented concrete sleeper B $91 \mathrm{~S} / 1$ with a piece of rail of UIC 60 type. The arrangement of model 15SD E10 in the experimental box showing the position of the rigid circular plate during plate load tests is displayed in Fig. 4. In order to measure the deflection, the track bed was fitted with bar displacement indicators with a loading area of $100 \times 100 \mathrm{~mm}$ with a protected measurement axis. The deflection was measured at depths of $175 \mathrm{~mm}$ and $350 \mathrm{~mm}$ under the sleeper loading area. At each depth, four displacement indicators were placed at identical positions. The deflection values were measured by mechanical and digital path indicators with a precision of $0.01 \mathrm{~mm}$. The location of the displacement indicators is shown in Fig. 5.
The measurements further included sleeper deflection due to rail load. For an axle load of $22.5 \mathrm{t}$ the maximum force acting on the rail was calculated as $P=50 \mathrm{kN}$, for an axle load of $25.0 \mathrm{t} P=60 \mathrm{kN}$, and for an axle load of $30.0 \mathrm{t} P=70 \mathrm{kN}$. The deflection measurements in the experimental box are illustrated in Fig. 6. Sleeper deflection and deflection values at individual track bed depths were measured following $30 \times$ repeated loading with force $P$ acting in three measurement cycles composed of loading and unloading phases. An example of the deflection results measured on model 30SD E25 is given in Table 3 .

In the rail head loading process, it must be considered that by increasing the rail head load from $P=50 \mathrm{kN}$ to $60 \mathrm{kN}$ or $75 \mathrm{kN}$ respectively, the load increase at $P=60 \mathrm{kN}$ amounts to $120 \%$ or to $150 \%$ at $P=75 \mathrm{kN}$.

\section{Results}

The deflection measurements on model 30SD E25 displayed in Table 3 provide the following results:

1. The deflection measurement method applying simple displacement indicators was suitable for determining the deflection values at various track bed depths, and the displacement indicators showed sensitivity in registering deflection values due to the changing rail head load.

2. A comparison of the deflection values for $P=50 \mathrm{kN}$ at a depth of $175 \mathrm{~mm}$ with those for $P=60 \mathrm{kN}$ or $75 \mathrm{kN}$, re-

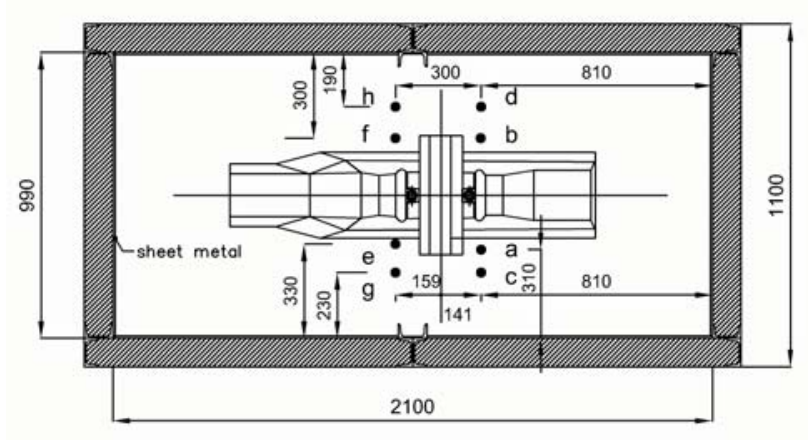

a)

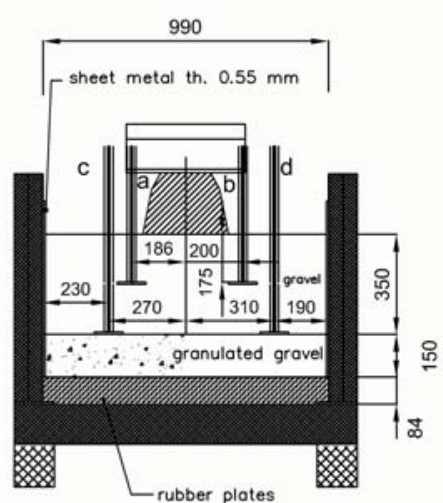

b)

Fig. 5 Arrangement and position of individual displacement indicators a) ground plan, b) cross section 


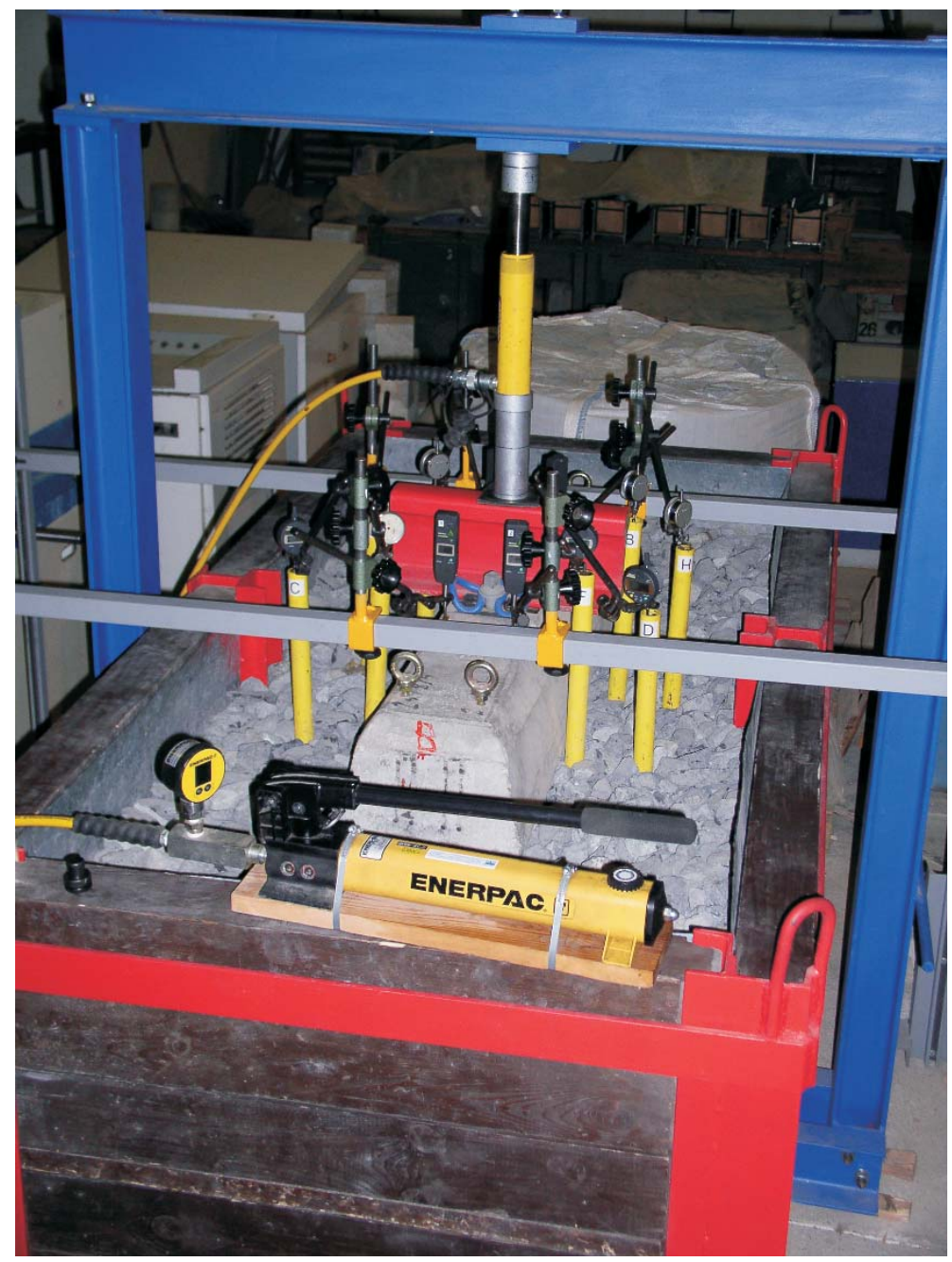

Fig. 6: Deflection measurement due to rail head load

spectively shows that the increase in the deflection values is $118 \%$ or $143 \%$ respectively, which roughly corresponds to the increased load acting on the rail head.

3. A comparison of the deflection values for $P=50 \mathrm{kN}$ at a depth of $350 \mathrm{~mm}$ with those for $P=60 \mathrm{kN}$ or $75 \mathrm{kN}$, respectively, shows that the increase in the deflection values is $117 \%$ or $150 \%$ respectively, which again roughly corresponds to the increased load acting on the rail head.

4. The deflection measurement results obtained on the models are in close accordance with the results of the numerical analysis.
Similar results were provided for other track bed structure models.

\subsection{Passage of carriages with an axle load of 22.5 t on railway tracks in the Czech Republic}

The passage of carriages with axle loads of $22.5 \mathrm{t}$ (present-day maximum axle load) on railway tracks in the Czech Republic is regulated by Instruction ČD S66 "Basic instruction for spatial passage and transition of carriages on railway tracks in the Czech Republic". The permitted axle load of

Table 3: Results of deflection measurements on track bed model 30SD E25

\begin{tabular}{|c|c|c|c|c|}
\hline \multirow{2}{*}{$\begin{array}{c}\text { Rail head loading } \\
\text { in } \mathbf{k N}\end{array}$} & \multicolumn{2}{|c|}{$\begin{array}{c}\text { Mean deflection under sleeper loading area } \\
\text { in mm }\end{array}$} & \multicolumn{2}{c|}{$\begin{array}{c}\text { Deflection increase } \\
\text { in \% }\end{array}$} \\
\cline { 2 - 5 } & at depth of $175 \mathrm{~mm}$ & at depth of $350 \mathrm{~mm}$ & at depth of $175 \mathrm{~mm}$ & at depth of $350 \mathrm{~mm}$ \\
\hline 50 & 0.28 & 0.12 & $100 \%$ & $100 \%$ \\
\hline 60 & 0.33 & 0.14 & $118 \%$ & $117 \%$ \\
\hline 75 & 0.40 & 0.18 & $143 \%$ & $150 \%$ \\
\hline
\end{tabular}


22.5 t corresponds to track load classes D3 and D4. The allowable load per linear meter for track load class D3 is $7.2 \mathrm{t} \cdot \mathrm{m}^{-1}$, and for track load class D4 the allowable load per linear meter is $8.0 \mathrm{t} \cdot \mathrm{m}^{-1}$. Instruction ČD S66 enumerates individual railway track sections, specifying the track load class permitted. The technical condition of railway tracks in the Czech Republic is specified in the "Outline of property management in SŽDC s.o. for 2004”, ref. No. 559/05/GǨ-013, May 2005.

Out of the total length of tracks of $9505.140 \mathrm{~km}$, an axle load of $22.5 \mathrm{t}$ is permitted only on $3454.785 \mathrm{~km}$, i.e. on $36.34 \%$. On all-national corridor tracks with a total length of $1460.068 \mathrm{~km}$, an axle load of $22.5 \mathrm{t}$ (track load class D4) is permitted on $1359.612 \mathrm{~km}$, i.e. on $93.11 \%$. The axle load permitted on the remaining corridor tracks is $20.0 \mathrm{t}$.

On other all-national tracks with a total length of $4872.816 \mathrm{~km}$, the axle load of $22.5 \mathrm{t}$ is permitted only on $1836.812 \mathrm{~km}$, i.e. $37.69 \%$. On the prevailing length of other all-national tracks, the permitted axle load of $20.0 \mathrm{t}$ applies to a length of $2843.108 \mathrm{~km}$, i.e. $58.43 \%$.

On regional tracks with a total length of $3170.640 \mathrm{~km}$, i.e. on $8.14 \%$, the permitted axle load of $20.0 \mathrm{t}$ applies to a length of $2051.487 \mathrm{~km}$, i.e. to $64.70 \%$. Only the remaining regional tracks have permitted axle loads of $16.0 \mathrm{t}$ to $18.0 \mathrm{t}$.

An analysis of the passage of carriages on the railway tracks in the Czech Republic shows that the corridor tracks, which have been recently modernized or optimized (the permanent way and substructure being reconstructed to achieve so-called optimum condition), are suited for the assessing of a potential increase in axle load. Other railway tracks are not suitable in this respect, as it would be too expensive.

\subsection{Assessment of a potential increase in axle load to 25.0 t on corridor tracks}

The existing corridor tracks in the railway network of the Czech Republic are in considerably better condition than the other all-national and regional tracks as they have gone through gradual modernization or optimization. Their technical condition shows the following characteristics:

1. The permanent way on corridor tracks includes:

- rail shapes of UIC 60 or R 65 type,

- resilient fixation without baseplates,

- concrete sleepers for resilient fixation without baseplates (the B $91 \mathrm{~S}$ type sleeper is dimensioned for axle loads of $25.0 \mathrm{t}$ and a speed of $160 \mathrm{~km} \cdot \mathrm{h}^{-1}$ ),

- a ballast bed $350 \mathrm{~mm}$ in thickness under the sleeper loading area,

- spacing of sleepers of $600 \mathrm{~mm}$.

The permanent way on corridor tracks complies with regulation UIC-KODEX $724 \mathrm{E}$ "Gleisbewehrung für 25 Tonnen $(250 \mathrm{kN})$ auf Schotteroberbau" of May 2005.

2. The substructure is composed of the stable track body of the former all-national railways, whose track bed was reconstructed during modernization or optimization to comply with the minimum required load-bearing capacity of substructure subgrade of $E_{p l}=50 \mathrm{MPa}$. When considering a potential increase in axle loads from $22.5 \mathrm{t}$ to $25.0 \mathrm{t}$ the load increase acting on the track bed amounts to $11.1 \%$. For this reason, it would also be in place to con- sider an increase in the minimum load-bearing capacity value $E_{p l}=50 \times 0.111=55.5 \mathrm{MPa}$. We may presume that due to modernization or optimization during which the track bed load-bearing capacity has been increased by applying non-cemented layers or layers of stabilized soil, increased substructure subgrade loading may be allowed.

3. On corridor tracks with a modernized permanent bed and substructure constructions railway operation with the axle load increased to 25.0 t may be allowed.

\subsection{Assessment of a potential increase in axle load to 30.0 t on corridor tracks}

An analysis of the technical condition of corridor tracks provides the following conclusions for a potential increase in axle loads to 30.0 t on corridor tracks:

1. The design parameters for permanent way construction for an axle load of $30.0 \mathrm{t}$ have not yet been defined. The permanent way structure would have to be improved by designing a new concrete sleeper for loading by 30.0 t potentially increasing the ballast bed thickness under the sleeper loading area.

2. The substructure would have to be designed for a track bed load increased by $50 \%$ (i.e. min. $E_{p l}=50 \times 1.5$ $=75 \mathrm{MPa}$ ). In order to reveal the current condition of the subtructure, a detailed geotechnical survey of the track bed would be necessary together with a reconstruction design.

3. An increase in axle loads to 30.0 t on corridor tracks is therefore presently not feasible.

\section{Discussion and Summary}

A numerical analysis of the effect of increased axle loads to $25.0 \mathrm{t}$ or $30.0 \mathrm{t}$ and also experimental measurements on track bed models lead to the following conclusions:

1. An axle load increase to $25.0 \mathrm{t}$ is possible only on corridor tracks with current axle load 22.5 t. The load-bearing capacity of the substructure subgrade must be increased at least by $11 \%$.

2. An axle load increase to $30.0 \mathrm{t}$ on railway tracks in the Czech Republic is presently not feasible.

\section{Acknowledgment}

This paper was written within research project No. $1 \mathrm{~F} 52 \mathrm{H} / 052 / 130$, funded by the Ministry of Transport of the Czech Republic.

\section{References}

[1] Krejčiříková, H., Tyc, P., Lidmila, M., Horníček, L., Voř́šsek, P., et al.: Methodology of Transitional Parameters for the Construction of Substructure on Tracks of the Conventional Trans-European System. Research reports of project 1F52H/052/130, Faculty of Civil Engineering, CTU in Prague, Department of Railway Structures, 2005 and 2006.

[2] Instruction $\check{C} D$ S4 Substructure, 1997 (in force since 1. 7. 1998).

[3] Instruction $\check{C} D S 3$ Permanent Way. 
[4] Instruction ČD S66 Basic Instruction for Spatial Passage and Transition of Carriages on Railway Tracks in the Czech Republic.

[5] Outline of Property Management in SŽDC s.o. for 2004, ref. No. 559/05/GŘ-013, May 2005.

[6] UIC-KODEX 724 E Gleisbewehrung für 25 Tonnen (250 kN) auf Schotteroberbau, 1. Ausgabe, Mai 2005.

Ing. Martin Lidmila, Ph.D.

e-mail: lidmila@fsv.cvut.cz

Ing. Leoš Horníček, Ph.D.

e-mail: hornicek@fsv.cvut.cz
Doc. Ing. Hana Krejčiříková, CSc.

phone: +420224354756

e-mail: krejcirikova@fsv.cvut.cz

Prof. Ing. Petr Tyc, DrSc.

e-mail: petr.tyc@fsv.cvut.cz

Department of Railway Structures

Czech Technical University in Prague

Faculty of Civil Engineering

Thákurova 7

16629 Praha 6, Czech Republic 